\title{
Complete response to pixantrone as a salvage therapy in a relapsed/refractory diffuse large B-cell lymphoma
}

\author{
Anna Pasternak \\ Clinical Department of Hematology, \\ Warmian-Masurian Cancer Center of the Ministry of the Interior and Administration's Hospital, \\ Olsztyn, Poland
}

Correspondence:

Anna Pasternak

Clinical Department of Hematology,

Warmian-Masurian Cancer Center of the Ministry of the Interior and Administration's Hospital 10-228 Olsztyn, al. Wojska Polskiego 37

Received: 16.06.2020 Accepted: 30.06.2020

DOI: 10.24292/O1.OR.220300620.5 Copyright $\odot$ Medical Education. All rights reserved.

\section{ABSTRACT}

Diffuse large B-cell lymphoma (DLBCL) is an aggressive form of non-Hodgkin lymphoma (NHL). It is one of the most common form of the disease. A combination of chemotherapy with anthracycline and a monoclonal antibody targeting CD20 is used as a I line therapy. About two out of three people with DLBCL achieve and maintain complete remission after this treatment. In case of relapse or refractory disease a salvage high-dose chemotherapy followed by autologous stem cell transplantation (HD-ASCT) is the standard of care. Patientrs who relapse after HD-ASCT have a very poor prognosis. Pixantrone is a new anthracycline derivative registered to treat relapsed/refractory DLBCL in adult patients. It is a cytostatic agent with a reduced cardiotoxicity comparing to classic anthracyclines. Herein, we report two cases of relapsed/refractory $D L B C L$ treated with pixantrone as a salvage therapy. The first case concernes a 58-year-old female patient with a diagnose of $\mathrm{DLBCL}$, who relapsed after four prior lines of therapy (R-CHOP, ICE, HD-Mtx, CSN radiation) and achieved complete remission after pixantrone therapy, but died of acute myeloid leukemia 3 months after the end of treatment. Second case is a story of a 75-year-old female patient treated with two prior lines of treatment (R-CHOP, R-IVE), who achieved complete remission after a III line of therapy with pixantrone. Pixantrone monotherapy proves to be effective in relapsed/refractory DLBCL. This treatment is well tolerated in a group of elderly patients and can be also used in a group of patients with a limited cardiac function.

Key words: cardiotoxicity, pixantrone, DLBCL lymphoma 


\section{INTRODUCTION}

Diffuse large B-cell lymphoma (DLBCL) is an aggressive form of non-Hodgkin lymphoma (NHL). It is one of the most common form of the disease, accounting for about $80 \%$ of all aggressive types of lymphomas [1, 2]. The incidence of DLBCL in Europe is estimated at a dozen per 100000 people/year and increases with age [1]. DLBCL lymphoma is highly sensitive to chemiotherapy and radiotherapy [1]. A combination of chemotherapy with anthracycline and a monoclonal antibody targeting CD20 is used as a I line treatment called R-CHOP (rituximab, cyclophosphamide, vincristine, doxorubicine, prednisone). About $70 \%$ of patients achieve complete remission after this frontline therapy, $10 \%$ have primary refractory disease, and another $20-35 \%$ relapse [3].

Diffuse large B-cell lymphomas are phenotypically and genetically heterogeneous. Development of a molecular diagnostics and gene-expression profiling helped to define subgroups of DLBCL according to cell of origin: the activated B-cell-like $(A B C)$ and germinal-center B-cell-like (GCB), leaving approximately 10 to $20 \%$ of cases "unclassified". In 2018 Schmitz et al presented a gene-expression classification of DLBCL subtypes based on genetic aberrations. This classification in operation with an international prognostic index (IPI) can help to identify patients, whose type of disease will not be curable with a standard I line therapy. In case of relapse or refractory disease a salvage high-dose chemotherapy followed by autologous stem cell transplantation (HD-ASCT) is the standard of care in patients under 65 years old with no serious comorbidities. As a salvage regiment in this group of patients can be given a platinum-based combination chemoterapy, including R-DHAP (rituximab, cisplatin, cytarabine, and dexamethasone), R-ICE (rituximab, ifosfamide, carboplatin, and etoposide). In case of another relapse an allogeneic stem cell transplantation can be considered. However, there is no currently recognized standard of care for patients who have failed I and II line treatment and for whom stem-cell transplantation is not an option.

In 1970's for the first time the anthracycline derivative (doxorubicin) was added to standard chemotherapy (COP, cyclophosphamide, prednisone, vincristine), which led to the breakthrough in the treatment of aggressive lymphomas. For the first time it was possible to achieve long-term disease remission or cure $[1,4]$. Unfortunately, using anthracyclines was strongly connected with cardiotoxicity. The mechanism of action of this group of agents is due in large part to the generation of free radicals, increased reactive nitrogen species formation in cardiomyocytes, nitration of myofibrils, and in effect myocardial contractility disorders, chemotherapy-induced oxidative stress and cellular injury. We observe also dysfunction of sodium-potassium and sodium-calcium pumps, which lead to overload cardiomyocytes with calcium ions and decrease of ATP (adenosine triphosphate) concentration. A consequence of these processes are either apoptosis or necrosis of cardiomyocytes, leading to left ventricle disfunction, cardiomyopathy, heart failure, myocardial infarction or thrombosis $[5,6]$. Furthermore, the symptoms which can appear are heart arrhythmias and arterial hypertension. This type of toxicity, called type I cardiotoxicity, is irreversible and lead to reduce of left ventricle ejection fraction (LVEF) [5]. After therapy including anthracyclines the risk of congestive heart failure rises up to $16 \%$, and asymptomatic cardiomyopathy even up to $57 \%$ [6]. The greatest risk factor for anthracycline-induced cardiotoxicity is the cumulative dose. Another identified risk factors, such as age, female gender, coexistence of cardiovascular diseases, prior mediastinal radiation etc., further increase the risk of toxicity.

A novel anthracenedione approved as monotherapy for treatment of relapsed or refractory aggressive diffuse B-cell non-Hodgkin's lymphoma is pixantrone. It is a first-in-class aza-anthracenedione, which differs from doxorubicin and mitoxantrone in its' unique chemical structure, and this results in differences in its mechanism of action. Pixantrone, comparing to doxorubicin and mitoxantrone, is only a weak inhibitor of topoisomerase II. Furthermore, it takes action in direct DNA alkylation, creating the pixantrone-DNA adducts and causing double-strand break. The removal of the hydroquinone groups from pixantrone's chemical structure makes pixantrone unable to bind iron and in turn promote iron-catalyzed oxidative damage. That explains why less cardiotoxicity is observed [8]. Its conditional approval in Europe was based on results from the open-label, randomized, PIX301study, where more patients who received pixantrone than comparator achieved a complete response (CR). This study randomised 140 patients $(1: 1)$ to treatment with either pixantrone or to an investigator chosen single-agent chemotherapy on the comparator arm (vinorelbine, oxaliplatine, iphosphamide, etoposide, mitoxantrone, gemcytabine, rituximab). Among patients treated with pixantrone complete remission rate was at $20 \%$, whereas in a group receiving comparator only $5,7 \%$. In addition, duration of $C R$ (complete response), OS (overal survival) and PFS (progression-free survival) were significantly prolonged in the pixantrone treatment group [10]. The most common adverse events in third or fourth grade of CTC (common toxicity criteria) reported during the pixantrone treatment were neutropenia, thrombocytopenia, weakness, skin and urine decoloration [12]. The recommended dose is $50 \mathrm{mg} / \mathrm{m}^{2}$ on days $1^{\text {st }}, 8^{\text {th }}$, and $15^{\text {th }}$ of each 28-day cycle for up to six cycles [8, 12]. In Poland pixantrone therapy has been conditionally approved for use and refunded since 2018. It is indicated as monotherapy for adult patients in 
III or IV line therapy, who previously achieved a durable response (at least 6 months of complete or partial response) to anthracycline or anthracenediones [11].

Herein, we report two cases of relapsed/refractory DLBCL treated with pixantrone as a salvage therapy.

\section{CASE REPORTS}

\section{First case}

A 54-year-old female patient presented with enlarged supraclavicular lymph nodes in August 2015. She was admitted to the department of surgery, where a computer tomography (CT) assessment revealed lymphadenopathy on both sides of the diaphragm and many small nodules in the pulmonary parenchyma. A supraclavicular lymph node biopsy was performed. Histological and immunohistochemical findings showed diffuse large B-cell lymphoma, NOS (non-other specified), subtype non-GCB CD20+, CD5-, CD10-, BCL2+, BCL6-/+, MUM1+, FOX, P1+, Ki-67 100\%, stage IVB IPI 3 with a lung and bone marrow involvement (fig. 1).

As a frontline therapy the patient received six cycles of R-CHOP with a central nervous system (CNS) prophylaxis with liposomal cytarabine. By February 2016 she had achieved a complete response.

In October 2016 control CT-scan revealed a new lymph node enlargement in abdominal cavity located next to right kidney vessels. A PET/CT scan confirmed a disease relapse. In case of relapse, the patient was qualified to a salvage high-dose chemotherapy (ICE) followed by autologous stem cell transplantation (HD-ASCT). In April 2017, after two cycles, the patient achieved partial response (PR). In June 2017, after completed three cycles of chemotherapy, the patient was admitted to the department of transplantology to stem cell mobilisation, which turned out to be unsuccessful. Because of grade third neutropenia subsequent cycles were delayed and the patient finally finished therapy after four cycles in September 2017. Control PET/CT-scan revealed a complete response (CR). The patient was reffered to a consolidating allogeneic stem cell transplantation from the matched sibling.

In December 2017 the patient admitted to the hospital due to vomiting and unconsciousness. CT assessment of central nervous system showed multiple lesions in brain, with the big gest one in right frontal lobe.

As a III line treatment a high-dose methotrexate monotherapy (HD-Mtx $2500 \mathrm{mg} / \mathrm{m}^{2}$ ) was administered. After two cycles partial response was attained, but after four cycles in April 2018 a control CT-scan revealed a disease progression (PD) (fig. 2). Adding radiation therapy of the brain (ten fractions, 3 Gy each) to chemotherapy allowed the patient to achieve a complete remission in May 2018. Already after four months form the end of treatment a PET/ CT scan showed a suspected lesion in stomach. Recurrent disease was histologically confirmed by tumor biopsy during gastroscopy.

After analysing clinical data, the patient met all the eligibility criteria and was qualified to pixantrone monotherapy treatment in a chemotherapy drug programme. Before first administration of the drug, all necessary laboratory and imaging tests were per-

FIGURE 1. Lung and bone marrow involvement (CT scan, October 2015).

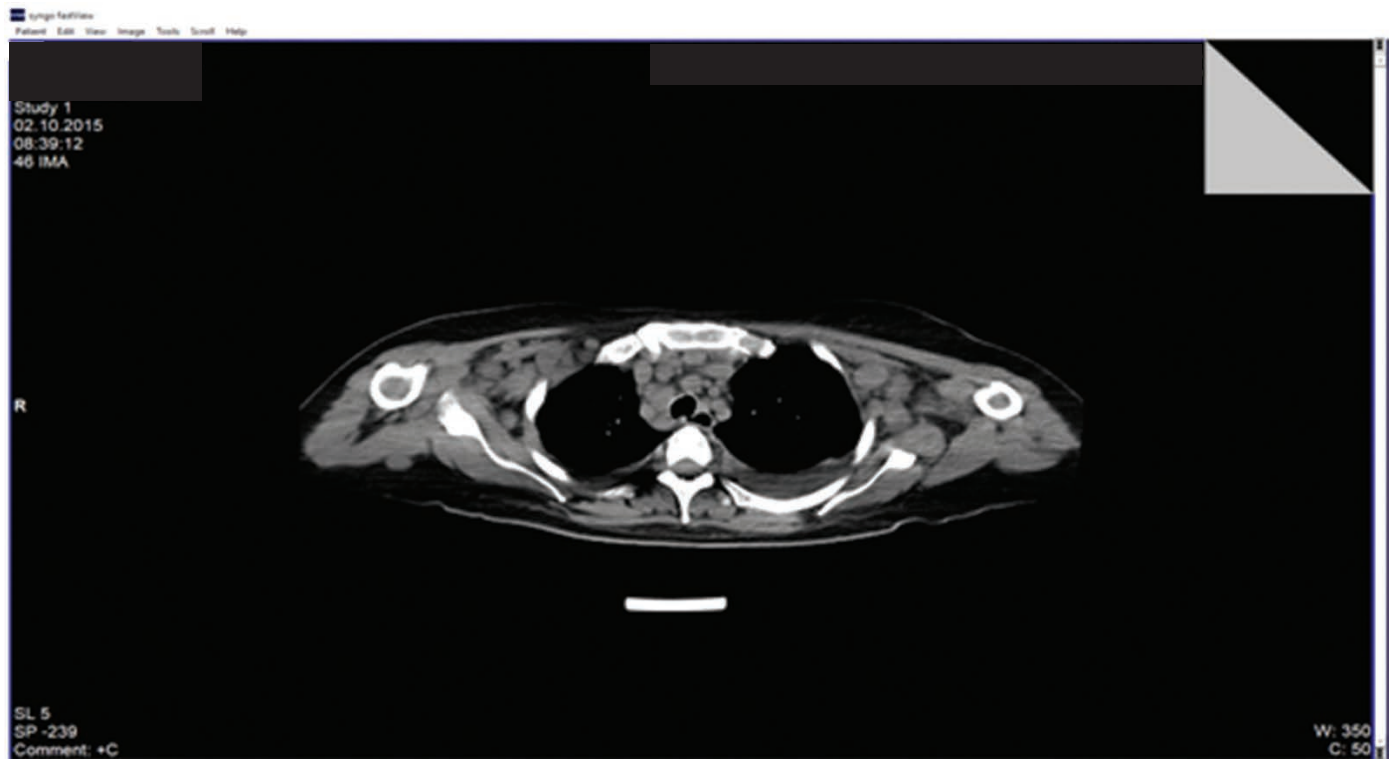


FIGURE 2. Disease progression after four cycles of chemotherapy (CT scan, April 2018).

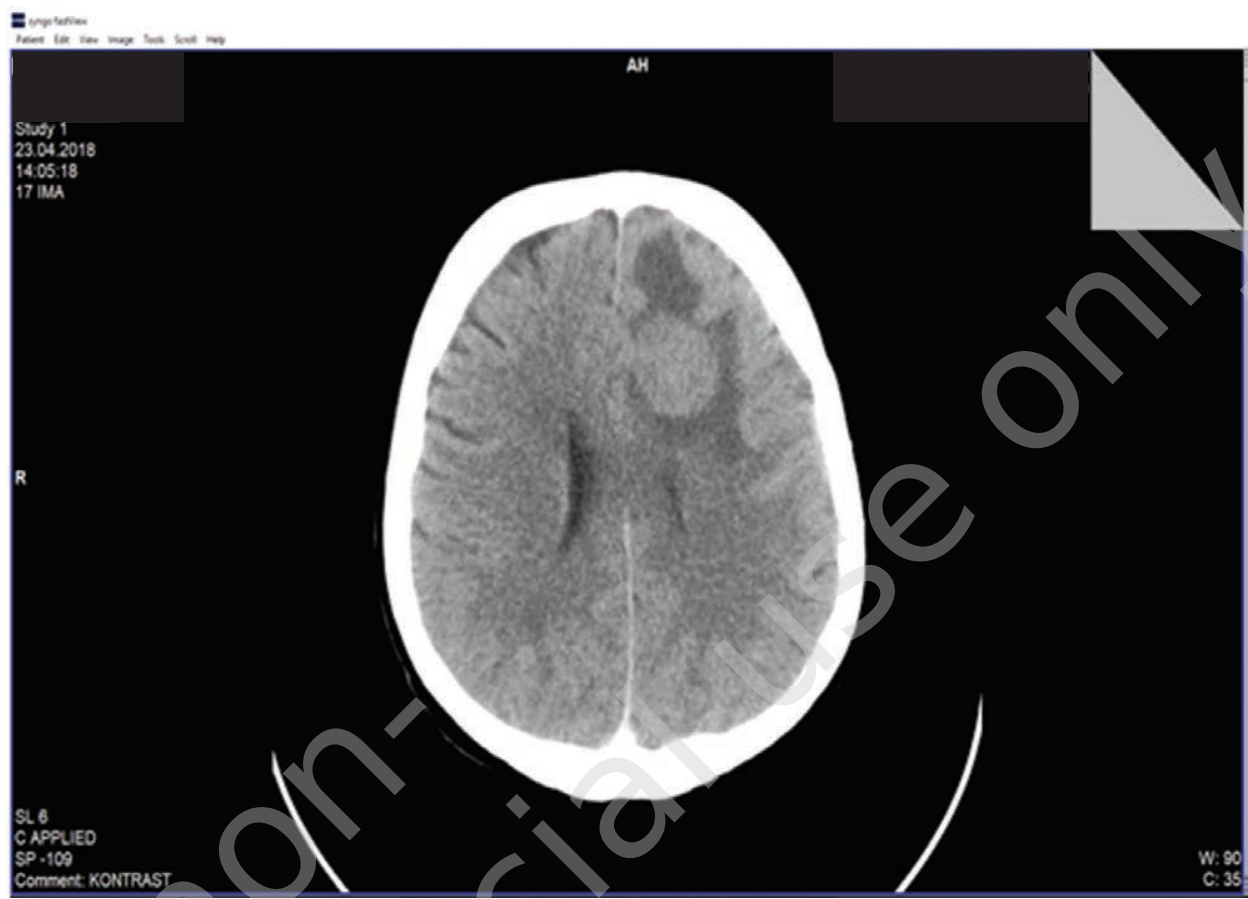

formed. An echocardiography showed minimal mitral and tricuspid valve regurgitation, correct heart cavity dimensions, left ventricle ejection fraction at $65 \%$, no left ventricular disfunction. During treatment, every two cycles echocardiography was repeated and did not show any decrease in LVEF from the baseline value or other abnormalities.

After four cycles of pixantrone monotherapy a control gastroscopy was performed. Histological and immunohistochemical findings showed only a chronic inflammation, without lymphoma infiltration. Treatment was completed in June 2019 without any missed doses. Dose of pixantrone was reduced at the beginning of fourth cycle to $80 \%$ of a starting dose because of recurrent neutropenia grade third and fourth, requiring the use of G-CSF (filgrastim) and dose delay. Despite neutropenia, infections or febrile neutropenia were not observed. Furthermore, the patient did not require any blood or platelets transfusions. No cardiac adverse events were observed. After the treatment was finished, in July 2019 a control PET/CT scan did not show any lesion in stomach, but a new lesion in right kidney was noticed. CT scan with iod contrast revealed a tumor $36 \times 31 \mathrm{~mm}$ in posterior parenchymal part of right kidney (fig. 3). The disease recurrence of DLBCL was the most probable diagnosis.

FIGURE 3. Tumor in posterior parenchymal part of right kidney (CT scan, August 2019).

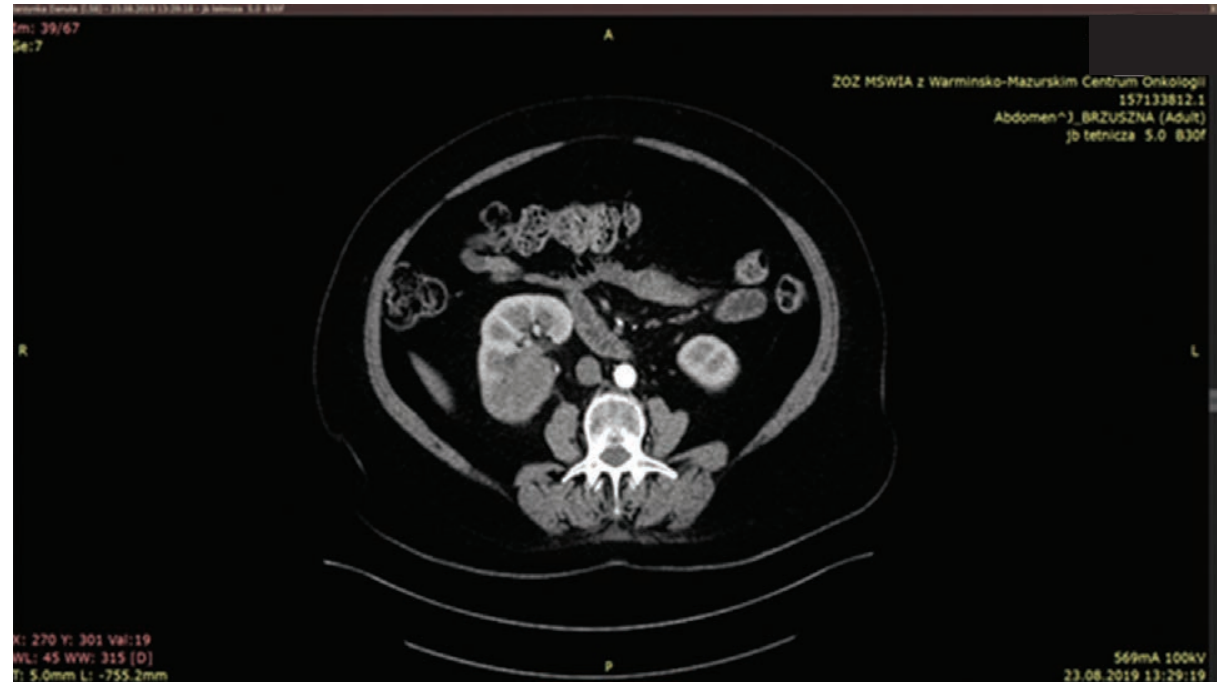


On September $9^{\text {th }}, 2019$ the patient admitted to a control visit in hematology department. A blood cell count revealed leucocytosis $26 \mathrm{G} / \mathrm{l}$ with elevated monocytosis ( $18.5 \mathrm{G} / \mathrm{l})$, trombocytopenia 16 000/ $\mu \mathrm{l}$ and moderate macrocytic anemia (Hgb $9.6 \mathrm{~g} / \mathrm{l}, \mathrm{MCV}$ $100.7 \mathrm{fl}$ ). Bone marrow biopsy and flow cytometry confirmed the diagnosis of acute monocytic leukemia. Because of appearance of secondary malignancy, systematic deterioration of the patient's general condition, she was qualified only to a best supportive care therapy with blood transfusions and hydroxyurea. The patient died on September 15 12019.

\section{Second case}

A 75-year-old female patient with arterial hypertension, had been diagnosed since April 2016 because of stomach ache for a few weeks. Abdominal ultrasonography did not show any pathology. Gastroscopy had been performed and revealed many small erosions of the mucosa and positive urease test. Histological test showed a chronic gastritis. She was treated with antibioticotherapy for eradication of $H$. pylori with good clinical effect.

October $27^{\text {th }}, 2016$ the patient was admitted to Emergency Unit because of suspection of upper gastrointestinal tract bleeding. The urgent gastroscopy revealed an active bleeding from gastric ulcer. A CT-scan was assessed and showed enlarged tumor-nodal mass located next to stomach wall and enlarged left supraclavicular lymph nodes. Histological and immunohistochemical findings in tumor biopsy showed diffuse large B-cell lymphoma, NOS (non-other specified), subtype non-GCB CD20+, CD5-, CD10-, $\mathrm{BCL2+,} \mathrm{BCL6+,} \mathrm{MUM1+,} \mathrm{FOX,} \mathrm{P1+,} \mathrm{Ki-67} \mathrm{90 \% ,} \mathrm{stage} \mathrm{IV} \mathrm{XB} \mathrm{IPI} 4$ with stomach involvement. As a frontline therapy the patient was qualified to R-COP (rituximab, vincristine, cyclophosphamide, prednisone) with doxorubicin (instead of doxorubicine because of mild diastolic left ventricle disfunction and gastrointestinal tract involvement). First cycle of immunochemotherapy was complicated by a second episode of gastric ulcer bleeding. After three cycles of treatment a control CT-scan and gastroscopy confirmed a partial response. By May 2017 she received eight cycles of immunochemiotherapy (one cycle of R-COP + doxorubicin and seven cycles of R-COP). According to PET/CT scan enlarged para-aortic lymph nodes were still metabolically active, what meant partial response. A CT scan assessed in December 2017 confirmed a disease progression in the location of previously described lesions (fig. 4).

In case of disease progression, the patient was qualified to a salvage high-dose chemotherapy R-IVE (rituximab, iphosphamide, etoposide, doxorubicine). After two and four cycles of this treatment, the partial response was persistent. The patient received two additional rituximab infusions. In August 2018, after completed the II line chemotherapy, the patient finally achieved complete remission (CR). The patient remained under observation in hematology outpatient clinic until February 2019, when she experienced a relapse. PET/CT scan revealed enlarged inguinal and iliac lymph nodes.

FIGURE 4. Disease progression (CT scan, December 2017).

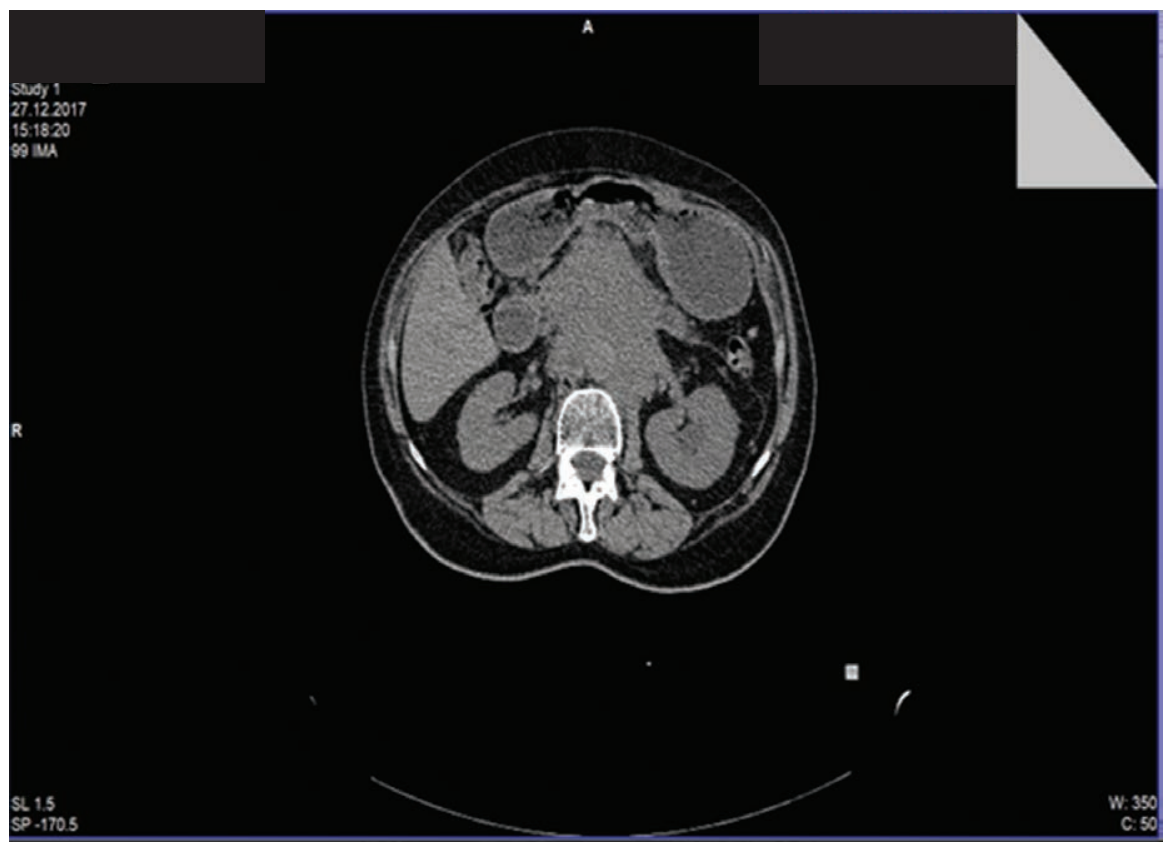


After analysing clinical data, the patient met all the eligibility criteria and was qualified to III line therapy for pixantrone in a chemotherapy drug programme. Before first administration of the drug, all necessary laboratory and imaging tests were performed. An echocardiography showed mild diastolic disfunction of left ventricle, minimal mitral and tricuspid valve regurgitation, correct heart cavity dimensions, left ventricle ejection fraction at $60 \%$. The patient started pixantrone monotherapy in February 2019 and received all six cycles of treatment. Every two cycles echocardiography was repeated and did not show any decrease in LVEF from the baseline value or any other abnormalities. Control CT-scan performed after four cycles showed a complete remission. Dose of pixantrone was reduced at the beginning of fourth cycle to $80 \%$ of a starting dose because of recurrent neutropenia grade second, requiring the use of G-CSF (filgrastim). Treatment was completed in July 2019 without any missed or delayed doses. Despite neutropenia, infections or febrile neutropenia were not observed. Furthermore, the patient did not require any blood or platelets transfusions. No cardiac adverse events were observed. The side effects were mouth dryness, skin and nails discoloration. After the treatment was finished, in July 2019 a control PET/CT scan confirmed complete remission (CR). After the end of treatment PET/CT scan is performed every 6 months. No disease progression is observed. The patient's last visit was in January 2020, she was asymptomatic, with no evidence of recurrent disease.

\section{DISCUSSION}

Pixantron in first patient's case was used as a V line therapy, which aimed to achieve a complete remission of the disease before a consolidating allogeneic stem cell transplantation from the matched sibling. It is indicated as monotherapy for adult patients in III or IV line therapy. The efficacy of pixantrone in V line treatment or more has not been proved in patients refractory to previous treatment line $[8,12]$. Nevertheless, the patient was able to get a therapeutic effect regarding the gastric tumor. Moreover, the patient completed all six cycles without any missed doses, the only adverse event observed was neutropenia CTC3, which was eliminated after dose reduction and adding G-CSF prophylaxis. This adverse event, besides trombocytopenia, is the most common side effect described in literature [18]. Because of sec- ondary malignancy and fast systematic deterioration of the patient's general condition, further diagnostics of renal tumor was impossible to perform.

Secondary malignancy in a form of acute myeloid leukemia most likely has been induced by cytostatic treatment, but it is impossible to define whether it was pixantrone's toxicity or prior high-dose multi-drug chemo- and radiotherapy. No secondary acute myeloid leukemia after the pixantrone monotherapy has been reported in available literature.

In case of a second patient pixantrone was administered as a III line therapy, which aimed to achieve a complete remission of the disease. Despite of an advanced age the patient completed the treatment without any missed or delayed doses. As in a previous case, the only adverse event was neutropenia CTC2, which was eliminated after dose reduction and adding G-CSF prophylaxis. Reported by the patient skin decoloration is described in literature as a characteristic and appears in $10 \%$ of patients [18]. It usually disappears after few weeks of drug elimination $[8,12]$.

In both cases pixantrone monotherapy turned out to be effective, due to good tolerability and without impairing patients' quality of life. Any of patients experienced a drug-induced cardiotoxicity. The cardiotoxicity of pixantrone therapy appears to be significantly lower than with other anthracyclines [17]. If it appears, it is most often associated with an asymptomatic decrease in ejection fraction [18].

\section{SUMMARY}

In summary, pixantrone is a valuable treatment in patients with multiply relapsed/refractory DLBCL lymphoma. This treatment is efficient and well tolerated in a group of heavily pretreated patients [15]. Pixantrone with its' significant antineoplastic efficacy and lower cardiotoxicity compared with other anthracyclines gives a chance to treat elderly patiens or patients with cardiac disfunction $[1,10]$. The use of this drug in combination therapy, often to replace doxorubicin or mitoxantrone, is currently being investigated in numerous studies [19]. Pixantrone is very promising in the aspect of minimalizing cardiotoxicity and improving the quality of life. 


\section{References}

1. Warzocha K, Puła B. Rozpoznawanie i leczenie chorych na chłoniaka rozlanego z dużych komórek B. Hematologia. $2017 ; 8(2): 113-31$.

2. Fisher SG, Fisher RI. The epidemiology of non-Hodgkin's lymphoma. Oncogene. 2004; 23(38): 6524-34. http://doi.org/10.1038/sj.onc.1207843.

3. Schuster SJ, Bishop MR, Tam CS et al. Tisagenlecleucel in Adult Relapsed or Refractory Diffuse Large B-Cell Lymphoma. N Engl J Med. 2019; 380(1): 45-56. http://doi.org/10.1056/NEJMoa1804980.

4. McKelvey EM, Gottlieb JA, Wilson HE et al. Hydroxyldaunomycin (Adriamycin) combination chemotherapy in malignant lymphoma. Cancer. 1976; 38(4): 1484-93. http://doi.org/10.1002/1097-0142(197610)38:4<1484::aid-cncr2820380407>3.0.co;2-i.

5. Neumann D, Korzeniowska K, Jankowski J et al. Kardiotoksyczność leczenia przeciwnowotworowego. Choroby Serca i Naczyń. 2016; 13(6): 434-44

6. Dudziak J, Słomczyński M, Torliński L. Powikłania kardiologiczne po chemioterapii - patomechanizm, diagnostyka, leczenie i zapobieganie. Choroby Serca i Naczyń. 2009; 6(2): 73-9.

7. Piętka I, Lelonek M. Kardiomiopatia poantracyklinowa - diagnostyka, leczenie i zapobieganie. Folia Cardiol Excerpta. 2010; 5(3): 130-4.

8. Péan E, Flores B, Hudson I et al. The European Medicines Agency review of pixantrone for the treatment of adult patients with multiply relapsed or refractory aggressive non-Hodgkin's B-cell lymphomas: summary of the scientific assessment of the committee for medicinal products for human use. Oncologist. 2013; 18(5): 625-33.

9. Pettengell R, Coiffier B, Egorov A et al. Long-Term Response and Remission with Pixantrone in Patients with Relapsed or Refractory Aggressive Non-Hodgkin Lymphoma: Post-Hoc Analysis of the Multicenter, Open-Label, Randomized PIX301 Trial. Clin Drug Investig. 2018; 38(6): 527-33. http:// doi.org/10.1007/s40261-018-0635-3.

10. Pettengell R, Coiffier B, Narayanan G et al. Pixantrone dimaleate versus other chemotherapeutic agents as a single-agent salvage treatment in patients with relapsed or refractory aggressive non-Hodgkin lymphoma: a phase 3, multicentre, open-label, randomised trial [published correction appears in Lancet Oncol. 2012; 13(7): e285]. Lancet Oncol. 2012; 13(7): 696-706. http://doi.org/10.1016/S1470-2045(12)70212-7.

11. Piksantron w leczeniu chłoniaków złośliwych. https://www.gov.pl/web/zdrowie/choroby-onkologiczne.

12. CTI Life Sciences Limited. Pixuvri: summary of product characteristics. 2017. http://www.ema.europa.eu/docs/en_GB/document_library/EPAR_ Product_Information/human/002055/WC500127968.pdf (Access: 10.07.2017).

13. Schmitz R, Wright GW, Huang DW et al. Genetics and Pathogenesis of Diffuse Large B-Cell Lymphoma. N Engl J Med. $2018 ; 378(15): 1396-407$. doi:10.1056/NEJMoa1801445.

14. Kaczmarczyk A, Giannopoulos K. Zmiany genetyczne w chłoniaku rozlanym z dużych komórek B. Acta Haematologica Polonica. 2019; 50(4): 204-14.

15. Pettengell R, Sebban C, Zinzani PL et al. Monotherapy with pixantrone in histologically confirmed relapsed or refractory aggressive B-cell non-Hodgkin lymphoma: post-hoc analyses from a phase III trial. Br J Haematol. 2016; 174(5): 692-9. http://doi.org/10.1111/bjh.14101.

16. Sancho JM, Navarro B, Soler Campos JA et al. Efficacy and safety of pixantrone for the treatment of multiply relapsed or refractory aggressive non-Hodgkin B-cell lymphomas. Eur J Haematol. 2020; 104(5): 499-508. http://doi.org/10.1111/ejh.13392.

17. Boyle EM, Morschhauser F. Pixantrone: a novel anthracycline-like drug for the treatment of non-Hodgkin lymphoma. Expert Opin Drug Saf. 2015; 14(4): 601-7. http://doi.org/10.1517/14740338.2015.1010505.

18. Péan E, Flores B, Hudson I et al. The European Medicines Agency review of pixantrone for the treatment of adult patients with multiply relapsed or refractory aggressive non-Hodgkin's B-cell lymphomas: summary of the scientific assessment of the committee for medicinal products for human use. Oncologist. 2013; 18(5): 625-33. http://doi.org/10.1634/theoncologist.2013-0020.

19. Barrenetxea Lekue C, Grasso Cicala S, Leppä S et al. Pixantrone beyond monotherapy: a review. Ann Hematol. 2019; 98(9): 2025-33. http://doi. org/10.1007/s00277-019-03749-0.

20. Engert A, Herbrecht R, Santoro A et al. EXTEND PIX301: a phase III randomized trial of pixantrone versus other chemotherapeutic agents as third-line monotherapy in patients with relapsed, aggressive non-Hodgkin's lymphoma. Clin Lymphoma Myeloma. 2006; 7(2): 152-4. http://doi.org/10.3816/ CLM.2006.n.055. 